\title{
Thermal Degradation of Polyisobutylene. Effect of Sample Size on Weight Loss
}

\author{
V. SRINIVASAN and S. V. BABU \\ Department of Chemical Engineering, Clarkson University, \\ Potsdam, NY-13676, U.S.A.
}

(Received May 21, 1984)

\begin{abstract}
KEY WORDS Thermal Degradation / Weight Loss / Polyisobutylene / Sample Size and Diffusion /
\end{abstract}

Thermal degradation of polyisobutylene was carried out by several workers. ${ }^{1-4}$ All the experiments involved the pyrolysis of relatively small quantities of the polymer, the sample size ranging from a few milligrams upto a hundred, and were done in vacuum. Such parameters were employed to minimize secondary effects like heat and mass transfer ${ }^{5}$ and secondary reactions. There is no study cited in the literature where quantitative experimental analysis of the weight loss as a function of the sample size is carried out for any of the polymers and under non-vacuum conditions, where secondary effects may be expected to be present. However the burning rates of polymers as a function of the particle diameter has been investigated for several polymers including polystyrene $^{6}$ and poly(methyl methacrylate). ${ }^{7}$ In the case of polystyrene it was found that the rate of weight loss increased with the diameter of the particle burned.

The result of employing a larger sample will be to slow down the transport of the volatile products from within the sample and/or to encourage secondary or reverse reactions of the products. By maintaining a swift stream of carrier gas over the sample, as is done in our experiments, quick removal of volatiles away from the surface of the sample is ensured, thereby decreasing external mass transfer ef- fects. The dimensions of the sample holder (an aluminum boat) in this experiment are such that the thickness of the polymer melt at the beginning of degradation is only about 4 $5 \mathrm{~mm}$ when pyrolysing 5 gram samples and correspondingly lower for $1 \mathrm{~g}$ and $100 \mathrm{mg}$ samples, thereby eliminating any temperature gradients within the sample. Higher sample weights were not considered to avoid problems associated with temperature gradients within the sample.

Thus when no temperature gradients exist and when the volatiles can be efficiently transported from the surface of the sample to the bulk of the carrier gas, a larger sample may be expected to show a lesser weight loss than a smaller one at any instant during degradation since they have the same cross-sectional area. This is because the time scale for diffusion of the volatiles in a larger sample is bigger than that for reaction as can be seen from the arguments below. The time scale of diffusion is given by $z^{2} / D$, where $z$ is the thickness of the sample and $D$ the diffusivity of the product gases in the polymer melt. Reliable values for $D$ are not available. Hence for our purposes a high value of $10^{-5} \mathrm{~cm}^{2} \mathrm{~s}^{-1}$ may be assumed ${ }^{8}$ to obtain a lower bound estimate for $z^{2} / D$ to be $2.5 \times 10^{4} \mathrm{~s}$ for $5 \mathrm{~g}$ samples based on an initial sample thickness of $0.5 \mathrm{~cm}$. The time 
scale for reaction is given by $1 / k$ ( $k$ is the rate constant) which is about $5 \times 10^{2}-5 \times 10^{3} \mathrm{~s}$ $\mathrm{min}^{-1}$ in the range of temperatures of interest. ${ }^{1}$

With this in mind, the degradation of 100 $\mathrm{mg}, 1 \mathrm{~g}$, and $5 \mathrm{~g}$ samples of polyisobutylene was carried out at 340,360 , and $380^{\circ} \mathrm{C}$, in a stream of nitrogen. The fifty-fold increase in the sample weight corresponds to a twentyfive-hundred-fold increase in the time scale for diffusion since the area of the sample is essentially constant. Our experimental results indicate that the $1 \mathrm{~g}$ sample has the same fractional weight loss as the $100 \mathrm{mg}$ sample, whereas the $5 \mathrm{~g}$ samples show a smaller weight loss at the lower temperature.

\section{EXPERIMENTAL}

Isothermal weight loss measurements were made for different durations of times in the following manner: A known quantity of the polymer was accurately weighed into a boat which was then moved into the pyrolysis zone with the help of a magnet. It was found that the temperature of the sample reached steady state in about two minutes for the $1 \mathrm{~g}$ and $0.1 \mathrm{~g}$ samples and in about $3 \mathrm{~min}$ for the $5 \mathrm{~g}$ sample. The thermocouple junction was in direct contact with the sample so that the temperature of the sample could be accurately monitored and controlled within $\pm 1^{\circ} \mathrm{C}$ continuously. After the required pyrolysis time the boat was pulled out of the zone, cooled and the weight loss determined. All the runs were conducted at a nitrogen flow rate of $80 \mathrm{scc} \mathrm{s}^{-1}$. As mentioned before experiments were conducted at three temperatures, viz, 340, 360, and $380^{\circ} \mathrm{C}$ and for three sample sizes of $5 \mathrm{~g}, 1 \mathrm{~g}$, and $100 \mathrm{mg}$.

\section{RESULTS}

The weight loss data is shown in Figure 1 where the fractional weight loss $x$ is plotted against time at three different temperatures and for the three sample sizes of $0.1 \mathrm{~g}, 1 \mathrm{~g}$, and $5 \mathrm{~g}$. It may be noted that the weight loss data for the two smaller samples can be represented within experimental error by the same curve for each of the three temperatures. This curve is drawn based on the first-order fit obtained from Figure 2. Further, the weight loss data for the larger $5 \mathrm{~g}$ sample also fall on these same curves at the two higher temperatures, again within experimental error. However, there is a substantial difference at $340^{\circ} \mathrm{C}$ which is the lowest temperature where we made measurements. We return to this point a little later on.

It has been established by Madorsky ${ }^{1}$ that the kinetics governing the degradation of small samples of polyisobutylene is first-order, i.e.,

$$
-\mathrm{d} W / \mathrm{d} t=k W
$$

where $W$ is the weight of the residue at any

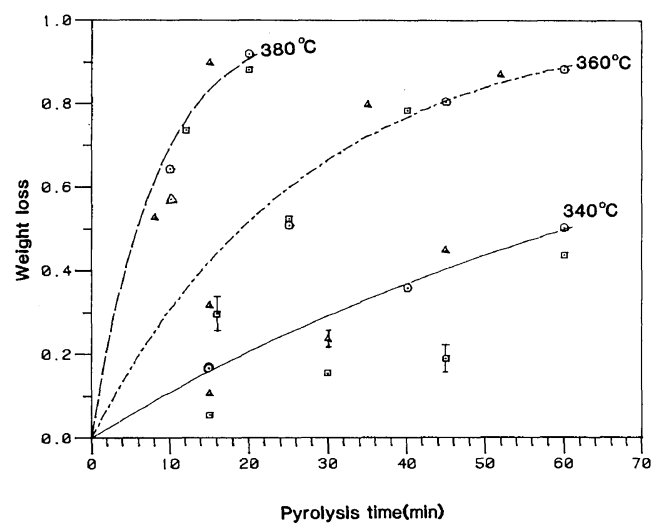

Figure 1. Weight loss curves: circles, $0.1 \mathrm{~g}$, triangles, $1 \mathrm{~g}$, and squares, $5 \mathrm{~g}$. I denotes typical error bar based on $2-3$ observations.

Table I. Comparison of rate constants

\begin{tabular}{|c|c|c|}
\hline \multirow{2}{*}{$\frac{T}{{ }^{\circ} \mathrm{C}}$} & \multicolumn{2}{|c|}{$\frac{k}{\min ^{-1}}$} \\
\hline & This work & Madorsky $^{1}$ \\
\hline 340 & $0.012 \pm 0.0025$ & 0.013 \\
\hline 360 & $0.037 \pm 0.004$ & 0.049 \\
\hline 380 & $0.12 \pm 0.024$ & 0.175 \\
\hline$E / \mathrm{kcal} \mathrm{mol}^{-1}$ & $46.9 \pm 2.9$ & 52.0 \\
\hline
\end{tabular}




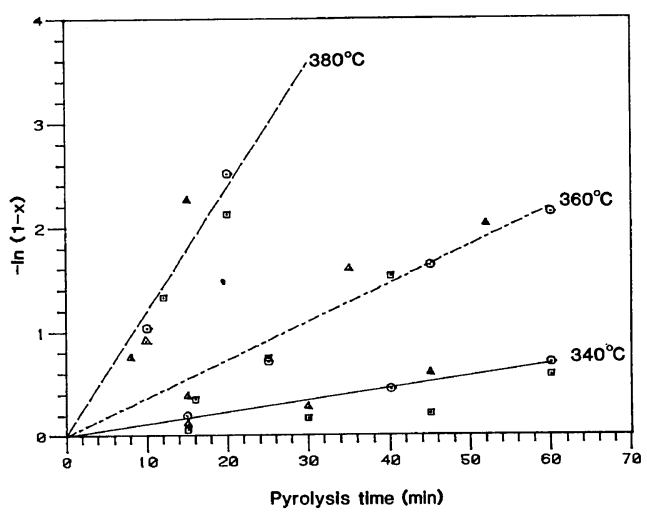

Figure 2. Plot of $-\ln (1-x)$ vs. $t$. Symbols are the same as in Figure 1.

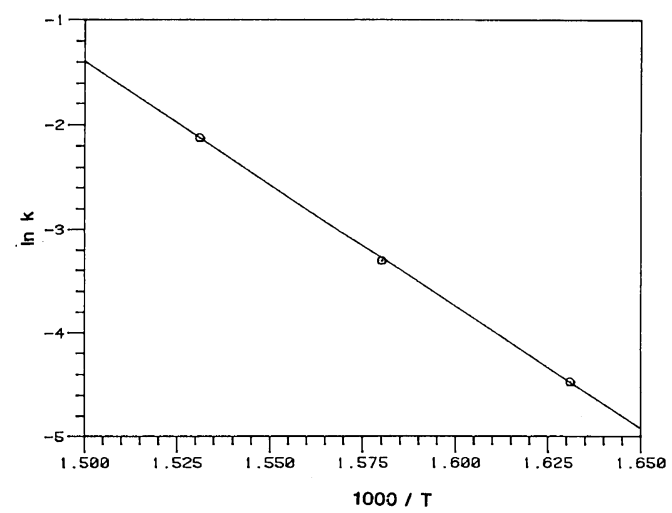

Figure 3. Arrhenius plot. The $k$ value for $340^{\circ} \mathrm{C}$ does not include data points for $5 \mathrm{~g}$ samples.

time $t$ and $k$ the first order rate constant $\left(\right.$ time $\left.^{-1}\right)$. The integrated from of eq 1 is given by:

$$
\ln [1 /(1-x)]=k t
$$

where $x$ is the fractional weight loss defined as $(1-W) / W_{0}$ and $W_{0}$ is the initial weight of the sample.

A plot of $\ln [1(1-x)]$ against $t$ is shown in Figure 2. The points representing $0.1 \mathrm{~g}, 1 \mathrm{~g}$, and $5 \mathrm{~g}$ are well represented by straight lines, one for each temperature of 360 and $380^{\circ} \mathrm{C}$. The slopes of these straight lines yield the rate constants and they are tabulated in Table I. It is also seen, however, from Figure 2 that at $340^{\circ} \mathrm{C}$ for the $5 \mathrm{~g}$ samples the points do not fall on the same straight line as that for the smaller samples and show significant deviation from first-order behavior. A detailed discussion of the mechanisms resulting in such behavior will be presented elsewhere for polypropylene, ${ }^{9}$ where it is noticed that significant deviation from first-order behavior occurs even with $0.1 \mathrm{~g}$ samples. In Table I the values of the rate constants (obtained by extrapolation of Madorsky's data at $320-340^{\circ} \mathrm{C}$ ) are also shown for comparison. Finally an Arrhenius plot of $\ln (k)$, with the values from Table I, against the reciprocal of temperature is shown in Figure 3. From the slope the activation energy is determined to be $46.9 \pm 2.9 \mathrm{kcal}$ $\mathrm{mol}^{-1}$ which is in good agreement with Madorsky's value of $52.0 \mathrm{kcal} \mathrm{mol}^{-1}$ (in the temperature range $320-340^{\circ} \mathrm{C}$ ). Considering that (i) the confidence limits of Madorsky's experimental results were not reported and (ii) the values of the rate constants have been extrapolated, the agreement in the rate constants and the activation energy between our findings and those of Madorsky is good.

\section{DISCUSSION}

Polyisobutylene is one of the polymers which degrades predominantly by an unzipping mechanism after initial chain break up, yielding substantial quantities of the monomer in the volatile product stream. ${ }^{2}$ The following represents a simplified scheme:

$$
\begin{aligned}
& \mathrm{RH} \rightarrow \mathrm{R} \cdot+\text { monomer } \quad\left(k_{\mathrm{a}}\right) \\
& \mathrm{R} \cdot \rightarrow \mathrm{R} \cdot+\text { monomer, etc. } \quad\left(k_{\mathrm{b}}\right) \\
& \mathrm{R} \cdot+\mathrm{R} \cdot \rightarrow \mathrm{G} \quad\left(k_{\mathrm{c}}\right) \\
& \mathrm{R} \cdot+\mathrm{RH} \rightarrow \mathrm{R} \cdot+\mathrm{G} \quad\left(k_{\mathrm{d}}\right)
\end{aligned}
$$

where $\mathrm{RH}$ represents the polymer, $\mathrm{R} \cdot \mathrm{a}$ polymeric radical and $G$, a volatile product (having a molecular weight higher than the monomer).

$[\mathrm{R} \cdot]$ itself is small because it depolymerizes instantly. ${ }^{1}$ Further the monomer content in the product gas is high, implying that $k_{\mathrm{d}} \ll k_{\mathrm{b}}$. 
Consequently,

$$
-\mathrm{d}[\mathrm{RH}] / \mathrm{d} t=k_{\mathrm{a}}[\mathrm{RH}]
$$

and this leads to a first-order system. Increasing the sample thickness by increasing the sample weight slows down the diffusion of the product gases to the melt surface allowing the reverse of the reactions (a) through (d) or other secondary reactions to occur with non-negligible rates. Consequently, the simple relationship between weight loss and time (eq 3 ) breaks down. The build up of diffusional resistance to a level where it is measurable through its effect on observed weight loss seems to be occurring in our $5 \mathrm{~g}$ samples at $340^{\circ} \mathrm{C}$, as can be seen in Figure 1. It may also be noted from this figure that the fractional weight loss we measured at $340^{\circ} \mathrm{C}$ for the $5 \mathrm{~g}$ samples is $40 \%$ or lower even after $60 \mathrm{~min}$ while at the higher temperatures of 360 and $380^{\circ} \mathrm{C}$ the weight loss measured is always higher than $30 \%$ due the relatively rapid rate of degradation. In other words by the time the weight loss can be measured accurately at these higher temperatures the weight of the sample is already down in the range of 3-3.5 g even though we started with $5 \mathrm{~g}$ samples. This is in contrast to the measurements at $340^{\circ} \mathrm{C}$ where the weight of the sample is always over this $3-3.5 \mathrm{~g}$ size. Similar comments can be made regarding the sample thickness since the area occupied by the polymer sample in the boat is essentially constant. Based on this constant area of about $10 \mathrm{~cm}^{2}$ it is possible to estimate the thickness of the sample to be about 0.3 to $0.35 \mathrm{~cm}$ when the weight is in the range of $3-3.5 \mathrm{~g}$. Consequently we are led to suggest that at sample thicknesses of $0.3-0.35 \mathrm{~cm}$ and greater the diffusional resistance becomes appreciable and begins to interfere with the kinetics. This reduces the weight loss. Using these values for the critical thickness it is possible to estimate a critical range for the dimensionless number $k z^{2} / D$ above which diffusion becomes important. However, here we are limited by the lack of a reasonably accurate estimate for $D$.

\section{REFERENCES}

1. S. L. Madorsky and S. Straus, J. Res. Natl. Bur. Stand., 53 (6), 361 (1964).

2. Y. Tsuchiya and K. Sumi, J. Polym. Sci., A-1, 7, 813 (1969).

3. S. L. Madorsky, S. Straus, D. Thompson, and L. Williamson, J. Polym. Sci., 4, 639 (1949).

4. R. McGuchan and I. C. McNeill, Eur. Polym. J., 4, 115 (1968).

5. J. Sestak, Talanta, 13, 567 (1966).

6. K. Kishore, K. Mohandas, and I. Spilda, Combust. Flame, 52, 215 (1983).

7. K. Seshadri and F. A. Williams, J. Polym. Sci., Polym. Chem. Ed., 16, 1755 (1978).

8. J. Crank and G. S. Park, "Diffusion in Polymers," Academic Press, London and New York, 1968.

9. S. V. Babu and V. Srinivasan, to be published. 